\title{
İntrahepatik Kolestazlı Gebelerde Maternal ve Fetal Sonuçların Değerlendirilmesi
}

\author{
Evaluation of Maternal and Fetal Outcomes in Intrahepatic Cholestasis of Pregnancy
}

Gültekin Adanaş AYDIN ${ }^{1}$, Gülten ÖZGEN ${ }^{2}$

1. Bursa Şehir Hastanesi, Kadın Hastalıkları ve Doğum Kliniği, Bursa, Türkiye

2. Bursa Yüksek İhtisas Eğitim ve Araştrıma Hastanesi, Kadın Hastalıkları ve Doğum Kliniği, Bursa, Türkiye

\section{$\ddot{O Z Z T T}$}

Amaç: Bu çalışmada kliniğimizde gebeliğin intrahepatik kolestazı(GIK) tanısı konmuş gebelerin maternal ve fetal sonuçlartdeğerlendirildi.

Gereçler ve Yöntem: Bu çalışma retrospektif olarak tasarlanmış olup, Eylül 2017 ve Eylül 2018 tarihleri arasinda toplam 53 hastayla yapıldı.GIKK tanısı kașıntı ve karaciğer enzimleri ile açlık safra asit düzeylerinde artış $(\geq 10 \mu \mathrm{mol} / \mathrm{L})$ artış olmast durumunda konuldu.Hastaların hastane kayttlarından doğum bilgileri ve demografik özelliklerine ulaşıldı.

Bulgular: Çalışmaya alınan hastaların yaş ortalaması $30.5 \pm 5.7$ yıl ve tanı anindaki gebelik yaşı ortalaması $32.3 \pm 2.8$ hafta olarak saptandi. Ortalama safra asit düzeyi $26.42 \pm 19.1 \mu \mathrm{mol} / \mathrm{Lo}$ larak hesaplandl.Hastaların \%26.4'ünde gestasyonel diyabet, $\% 15.1$ 'inde preeklampsi görüldü.Hastaların \%37.7'sinin preterm doğum yaptı̆̆ tespit edildi.Yenidoğan bebeklerin \%32.7 si yenidoğan yoğun bakım ünitesine alınırken, \%32.7 sinde yenidoğan geçici taşipnesi, \%33.3'ünde respiratuvar distres sendromu gelişstiği görüldü.Perinatal mortalite ise saptanmad.

Sonuç: Çalıșma sonuçlarımıza göre, GIKK takibinde en önemli unsurlar olan perinatal mortalite ve morbiditeyi azaltmak için hastaların yakın takibi ve şiddetli kolestaz bulguları olan hastaların belirlenip uygun tedavinin erken başlanması oldukça önemlidir.

Anahtar Kelimeler: gebelik, intrahepatik kolestaz, preterm dogum

\section{ABSTRACT}

Objective: In this study, we aimed to evaluate maternal and fetal outcomes in pregnant women diagnosed with intrahepatic cholestasis of pregnancy (ICP) in our clinic.

Material and Methods: In this retrospective study, we included a total of 53 patients with ICP who were admitted to Bursa Yüksek Ihtisas Training and Research Hospital, Obstetrics and Gynecology outpatient clinics between September 2017 and September 2018. The diagnosis of ICP was made based on elevated liver enzymes and bile acids $(\geq 10 \mu \mathrm{mol} / \mathrm{L})$ and pruritis. Delivery outcomes and demographic characteristics of the patients were obtained from the hospital records.

Results: The mean age of the patients was $30.5 \pm 5.7$ years and the mean gestational age was $32.3 \pm 2.8$ weeks. The mean bile acid level was $26.42 \pm 19.1 \mu \mathrm{mol} / \mathrm{L}$. Of the patients, $26.4 \% \mathrm{had}$ gestational diabetes mellitus and $15.1 \%$ had preeclampsia. A total of $37.7 \%$ of the patients had preterm delivery. Of all neonates, $32.7 \%$ required neonatal intensive care unit stay, while $32.7 \%$ had transient tachypnea of the newborn and 33.3\% had respiratory distress syndrome. No perinatal mortality was observed.

\section{İletişim}

Sorumlu Yazar: Gültekin Adanaş AYDIN

Adres: Bursa Şehir Hastanesi, Kadın Hastalıkları ve Doğum Kliniği,16110,Bursa, Türkiye

Tel: +90 (544) 8608282

E-Posta: gadanas@gmail.com

Makale Geliş: 04.04.2020

Makale Kabul: 29.05.2020

DOI: http://dx.doi.org/10.16948/zktipb.714219
Conclusion: Our study results suggest that close follow-up and identification of patients with severe cholestasis symptoms are the mainstays of the follow-up of ICP and early treatment to decrease perinatal mortality and morbidity.

Keywords: pregnancy, intrahepatic cholestasis, preterm delivery

\section{GIRIŞ}

Gebeliğin intrahepatik kolestazı(GIK), sıklıkla üçüncü trimesterde veya ikinci trimesterin sonlarında ortaya çıkan gebeliğge özgü bir durumdur. Vücutta kaşıntı, karaciğer enzimleri ve açlık safra asit düzeylerinde $\operatorname{artış}(\geq 10 \mu \mathrm{mol} / \mathrm{L})$ ile komplike olan bir durumdur[1,2]. Preterm doğum, fetal asfiksi,mekonyumlu amniyon sıvısı ve ölü doğum gibi istenmeyen perinatal morbidite ve mortalite ile ilişkilidir [3].

İnsidansı ülkeler arasında farkl111k göstermekle birlikte, $\% 0.1$ ila $\% 2$ arasında değişir ve en s1k İskandinav ve Güney Asya rrklarında görülür [4]. Her ne kadar GİK'inetiyolojisi tam olarak anlaşılamamış olsa da, multifaktöriyel olduğu düşünülmektedir. Artmış seks hormon sentezi, çevresel faktörler ve genetik yatkınlığın rol oynadığı tahmin edilmektedir $[4,5]$.Hastalığın ailesel dağılım göstermesi ve insidansın etnik gruplar arasında farklılık göstermesi,popülasyona özgü genetik risk faktörlerinin olduğunu düşündürmektedir [4].

Genel olarak GIK, serum safra asit düzeyleri dikkate alınarak hafif(10-40 $\mu \mathrm{mol} / \mathrm{L})$ ve ağır $>400$ $\mu \mathrm{mol} / \mathrm{L}$ ) diye sinıflandırılmaktadır [6].GİK'intedavisinde maternal semptomların azaltılmasinda ursodeoksikolik asit ilk tercihtir [7].Her ne kadar doğum için ideal doğum zamanı net değilse de, çalışmalarda sıklıkla 36-37.gebelik haftaları önerilmektedir $[3,8]$.

$\mathrm{Bu}$ çalışmada kliniğimizde GíK tanısı konan hastaların maternal ve fetal sonuçları değerlendirildi.

\section{GEREÇ ve YÖNTEM}

Bu retrospektif çalışmaya Eylül 2017 ve Eylül 2018 tarihleri arasında GíK tanısı konmuş toplam 53 hasta alındı. Kolestaz tanısı, kaşıntı şikayeti ile birlikte karaciğer enzimleri ve açlık safra asit düzeylerinde yükseklik olması durumunda konuldu. Safra asit düzeylerinin $10 \mu \mathrm{mol} / \mathrm{L}$ üzerinde olmas1 kolestaz açısından anlamlı bulundu. Hastalık tanısının konulması aşamasında kronik karaciğer hastalığ olan, anormal serolojik testlere sahip (hepatit A, B ve C) veya ultrasonografik incelemede safra 
yollarında tıkanıklık görülen hastalar çalışmaya dahil edilmedi.

Gebeliğin intrahepatik kolestazı tanısı için hastalardan kan örneği alınarak açlik safra asit düzeyleri, aspartat aminotransferaz (AST), alanin aminotransferaz (ALT), bilirübin,alkalen fosfataz (ALP) ve laktat dehidrogenaz ( $\mathrm{LDH})$ ve viral hepatitlerin serolojisi çalışıldı.Ayrıca tüm hastalara abdominal ultrasonografi yapıld1. Hastaların hastane kayıtlarından gebeliklerinin spontan yada in vitro fertilizasyon (IVF) olup olmadığ 1 , sistemik hastalık öyküleri, ilaç ve sigara kullanım öyküleri,önceki gebeliklerinde kolestaz öyküsü olup olmadığı, bu gebeliklerinde preeklampsi (PE), gestasyonel diabetes mellitus (GDM) gelişip gelişmediği ve tanı anındaki gebelik haftaları kaydedildi. Peripartum sonuçlarını değerlendirmek için doğum haftaları, doğum şekli,doğum ağırlığı,APGAR skorları,amniyon sıvısında mekonyum olup olmadığı veyenidoğan ünitesine alınıp alınmadığı dosya bilgilerinden incelenerek kaydedildi.

Hastanemizde GIKK tanısı konan hastalara ursodeoksikolik asit tedavisi günde üç kez $250 \mathrm{mg}$ olacak şekilde başlanmaktadır.Hastaların takibine 36 ila 37. haftaya kadar devam edilmekte, ancak maternal veya fetal durumda bozulma olası durumunda, doğum daha erken haftalara alınabilmektedir.

\section{İstatistiksel Analiz}

İstatistiksel analiz SPSS versiyon 22.0 yaz1lımı (IBM Corp., Armonk, NY, ABD) ile yapıldı. Elde edilen verilerin dağılım ve türlerine bağlı olarak tanımlayıcı istatistikler ortalama, standart sapma (SS), dağılım (minimum-maksimum), sayı ve yüzde olarak hesapland1. Kategorik yapıdaki demografik ve klinik bulgular arasındaki ilişkiler uygun ki-kare testleri ile incelendi. İstatistiksel anlamlılık düzeyi olarak $\mathrm{p}<0.05$ kabul edildi.

\section{BULGULAR}

Çalışmaya GİK tanısı konan toplam 53 hasta dahil edildi.Çalışmaya alınan hastaların yaş ortalaması $30.5 \pm 5.7$ ve vücut kitle indeks ortalamas1 $28 \pm 3.9 \mathrm{~kg} / \mathrm{m} 2$ olarak saptand1. Hastaların tanı anında gebelik haftası ortalamas1 $32.3 \pm 2.8$ ve doğum haftas1 ortalaması ise $35.8 \pm 2.4$ olarak saptand1. Hastalara ait demografik bilgiler Tablo 1'de verildi.

Tablo 1: Çalışmaya alınan hastalara ait demografik bilgiler.

\begin{tabular}{|l|l|l|l|}
\hline & N & Ortalama & $\begin{array}{c}\text { Standart } \\
\text { Sapma }\end{array}$ \\
\hline Yaş(yıl) & 53 & 30.566 & 5.766 \\
\hline VKİ (kg/m²) & 53 & 28.072 & 3.940 \\
\hline Tanı anında gebelik haftası & 53 & 32.396 & 2.803 \\
\hline Doğum haftası & 51 & 35.824 & 2.488 \\
\hline Doğum ağırlığı(g) & 51 & 2730.647 & 703.254 \\
\hline Gravida & 53 & 2.434 & 1.487 \\
\hline Parite & 53 & 1.019 & 0.930 \\
\hline Düşük sayısı & 53 & 0.415 & 0.795 \\
\hline
\end{tabular}

Çalışmaya alınan hastaların \%18.9'unda IVF gebelik,\%13.2'sinde ise ikiz gebelik mevcuttu. Hastaların sadece birinde $(\% 0.53)$ önceki gebelikte kolestaz öyküsü mevcuttu.Hastaların üçünde (\%5.7) sigara kullanımı mevcuttu.Hastaların takiplerinde kolestaz haricinde \%26.4'ünde GDM,\%15.1'inde $\mathrm{PE}$ ve \%11.3'ünde ise intrauterin gelişim geriliği (IUGR) saptand1.

Tablo 2: Hastalara ait kategorik tipteki özellikler.

\begin{tabular}{|c|c|c|c|}
\hline \multicolumn{2}{|l|}{ Değișken } & \multirow{2}{*}{$\begin{array}{c}\mathrm{n} \\
50\end{array}$} & \multirow{2}{*}{$\begin{array}{r}\% \\
94.3\end{array}$} \\
\hline \multirow{2}{*}{ Sigara } & Yok & & \\
\hline & Var & 3 & 5.7 \\
\hline \multirow{2}{*}{ IVF gebelik } & Yok & 43 & 81.1 \\
\hline & Var & 10 & 18.9 \\
\hline \multirow{2}{*}{ Spontan gebelik } & Yok & 13 & 24.5 \\
\hline & Var & 40 & 75.5 \\
\hline \multirow{2}{*}{ İkiz gebelik } & Yok & 46 & 86.8 \\
\hline & Var & 7 & 13.2 \\
\hline \multirow{2}{*}{$\begin{array}{l}\text { Önceki gebelikte } \\
\text { kolestaz öyküsü }\end{array}$} & Yok & 52 & 98.1 \\
\hline & Var & 1 & 1.9 \\
\hline \multirow{2}{*}{$\begin{array}{l}\text { Gebelik başında progesteron } \\
\text { kullanımı }\end{array}$} & Yok & 24 & 46.2 \\
\hline & Var & 28 & 53.8 \\
\hline \multirow{2}{*}{ Kronik hipertansiyon } & Yok & 53 & 100.0 \\
\hline & Var & 0 & 0.0 \\
\hline \multirow{2}{*}{ GDM } & Yok & 39 & 73.6 \\
\hline & Var & 14 & 26.4 \\
\hline \multirow{2}{*}{ IUGR } & Yok & 47 & 88.7 \\
\hline & Var & 6 & 11.3 \\
\hline \multirow{2}{*}{ PE } & Yok & 45 & 84.9 \\
\hline & Var & 8 & 15.1 \\
\hline \multirow{5}{*}{ Kan grubu } & Diğer & 46 & 86.8 \\
\hline & $\operatorname{Arh}(-)$ & 4 & 7.5 \\
\hline & $\operatorname{Brh}(-)$ & 0 & 0.0 \\
\hline & ABrh(-) & 1 & 1.9 \\
\hline & Orh(-) & 2 & 3.8 \\
\hline \multirow{6}{*}{ Tüm batın USG incelemesi } & Normal & 29 & 54.7 \\
\hline & Kolesistektomi & 3 & 5.7 \\
\hline & Karaciğerde yağlanma & 6 & 11.3 \\
\hline & Safra kesesinde taş & 4 & 7.5 \\
\hline & Safra kesesinde yoğunluk & 4 & 7.5 \\
\hline & Dalak boyutu artmış & 1 & 1.9 \\
\hline \multirow{2}{*}{ İndüksiyon } & Yok & 29 & 56.9 \\
\hline & Var & 22 & 43.1 \\
\hline \multirow{2}{*}{ Propess $®$ kullanımı } & Yok & 40 & 78.4 \\
\hline & Var & 11 & 21.6 \\
\hline \multirow{2}{*}{ PPROM varlığ 1} & Yok & 49 & 96.1 \\
\hline & Var & 2 & 3.9 \\
\hline \multirow{2}{*}{ Dekolman } & Yok & 52 & 100.0 \\
\hline & Var & 0 & 0.0 \\
\hline & Yok & 50 & 96.2 \\
\hline Aton1 & Var & 2 & 3.8 \\
\hline Ölü doğum & Yok & 52 & 100.0 \\
\hline Cincivet & Erkek & 26 & 50.0 \\
\hline Cinsiyet & Kadın & 26 & 50.0 \\
\hline 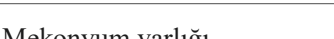 & Yok & 47 & 94.0 \\
\hline Mekonyum varlig1 & Var & 3 & 6.0 \\
\hline YYRÜ̈ watisi & Yok & 35 & 67.3 \\
\hline Y YBU yatış1 & Var & 17 & 32.7 \\
\hline RDS & Yok & 34 & 66.7 \\
\hline RDS & Var & 17 & 33.3 \\
\hline TTN & Yok & 35 & 67.3 \\
\hline $111 \mathrm{~N}$ & Var & 17 & 32.7 \\
\hline Hinerhilirïhinemi & Yok & 46 & 88.5 \\
\hline 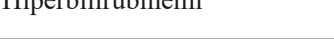 & Var & 6 & 11.5 \\
\hline Perinatal mortalite & Yok & 50 & 100.0 \\
\hline
\end{tabular}

a: Fisher kesin testi; $\boldsymbol{b}$ : Fisher-Freeman-Halton testi; $\boldsymbol{c}:$ Pearson ki-Kare testi. IVF: in vitro fertilizasyon; GDM: gestasyonel diabetes mellitus, IUGR: intrauterin gelişim geriliği; PE: preeklampsi; PPROM: preterm

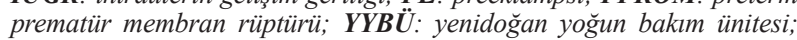
RDS: respiratuvar distres sendromu; TTN: yenidoğan geçici taşipnesi 
Hastaların yapılan batın ultrasonografi incelemelerinde ise, $\% 45.3$ 'ünde patolojik bulgulara rastlandi.Hastaların \%6'sinda amniyon sivisinda mekonyum mevcuttu. Yenidoğan bebeklerin \%32.7'si yenidoğan yoğun bakım ünitesine (YYBÜ) al1nırken, \%32.7'sinde yenidoğan geçici taşipnesi, $\% 33.3$ 'ünde respiratuvar distres sendromu (RDS) ve \%11.5'inde ise hiperbilirübinemi geliştiği görüldü. Perinatal mortalite ise saptanmadi. Hastalara ait kategorik tipteki özellikler Tablo 2'de verildi.

Hastalara ait laboratuvar parametreleri ise Tablo 3 'te verildi. Hastaların AST ortalamas1 $90.3 \pm 79.3$ IU/L, ALT ortalamas $124.86 \pm 122 \mathrm{U} / \mathrm{L}$ ve safra asitleri ortalaması ise $26.42 \pm 19.1 \mu \mathrm{mol} /$ Lolarak saptand.

Tablo 3: Hastalara ait laboratuvar parametreleri.

\begin{tabular}{|c|c|c|c|}
\hline & $\mathbf{N}$ & Ort. & SS \\
\hline $\mathrm{Hb}(\mathrm{g} / \mathrm{dL})$ & 53 & 12.974 & 13.656 \\
\hline AST(IU/L) & 53 & 90.358 & 79.356 \\
\hline ALT(U/L) & 53 & 124.868 & 122.018 \\
\hline GGT(U/L) & 20 & 24.200 & 20.135 \\
\hline Total bilirübin (mg/dl) & 50 & 0.803 & 0.479 \\
\hline Direkt bilirübin $(\mathrm{mg} / \mathrm{dl})$ & 50 & 0.328 & 0.274 \\
\hline $\mathrm{WBC}\left(10^{\wedge} 3 / \mu \mathrm{L}\right)$ & 53 & 12196.038 & 16503.839 \\
\hline $\operatorname{PLT}\left(10^{\wedge} 3 / \mu \mathrm{L}\right)$ & 53 & 252415.094 & 98671.645 \\
\hline Fibrinojen (mg/dl) & 53 & 587.132 & 135.469 \\
\hline $\mathrm{PT}(\mathrm{sn})$ & 53 & 13.523 & 1.131 \\
\hline APTT(sn) & 53 & 27.885 & 2.803 \\
\hline INR & 53 & 0.988 & 0.072 \\
\hline $\mathrm{LDH}(\mathrm{U} / \mathrm{L})$ & 31 & 224.452 & 42.444 \\
\hline $\operatorname{ALP}(\mathrm{U} / \mathrm{L})$ & 31 & 200.742 & 65.545 \\
\hline Kreatinin $(\mathrm{mg} / \mathrm{dL})$ & 53 & 0.637 & 0.103 \\
\hline Safra asidi $(\mu \mathrm{mol} / \mathrm{L})$ & 53 & 26.427 & 19.183 \\
\hline
\end{tabular}

SS: standart sapma; $\boldsymbol{H b}$ : hemoglobin; $\boldsymbol{A S T}$ : aspartat aminotransferaz; $\boldsymbol{A L T}$ : alanin aminotransferaz; $\boldsymbol{G G T}$ : gama glutamil transferaz; $\boldsymbol{W B C}$. beyaz kan hücresi; PLT: trombosit; PT: protrombin zamani; $\boldsymbol{A P T T}$ : aktive parsiyel tromboplastin zamani; INR: uluslararası normalleştirilmiş oran $\mathbf{L D H}$ : laktat dehidrogenaz; $\boldsymbol{A L P}$ : alkalen fosfataz

\section{TARTIŞMA}

Çalışmamızda kliniğimizde GíK tanısı konan hastalara ait maternal ve fetal sonuçlardeğerlendirildi.Yapılan çalışmalarda GİK tanısı konan hastalarda PE ve GDM için risk artışı tespit edilmiștir [912]. Bizim de çalışmamızda hastaların \%26.4'ünde GDM,\%15.1'inde ise PE saptand. Bu saptanan oranların normal gebelikte görülen oranlara kıyasla artmış olduğu belirlendi. Hastalarımızın sadece $\% 11.3$ 'ünde IUGR tespit edildi.Literatürde s1klıkla GİK hastalarında daha düşük oranlarda IUGR saptanmıştır [13, 14]. Mor ve ark. [13] GİK'ingeç başlangıçlı PE için bir risk faktörü olduğunu; ancak erken başlangıçlı PE ve buna bağlı gelişecek gelişme geriliği için riski artırmadığını bulmuştur.

Her ne kadar GİK anne için daha benign bir durum olsa da, fetüs için preterm doğum,fetal distres,amniyon sivisinda mekonyum olmas1 ve intrauterin ölüm gibi olumsuz durumların görülebildiği bir hastalıktır.Yapılan çalışmalarda serum safra asit düzeylerinin $40 \mu \mathrm{mol} / \mathrm{L}$ üzerinde olması durumun- da fetal komplikasyonların daha fazla olduğu görülmüştür $[6,13]$. Fetal distres ve amniyon sivisinda mekonyum bulunma sıklığının da, yine safra asit düzeylerinin $40 \mu \mathrm{mol} / \mathrm{L}$ üzerinde olması durumunda arttığı görülmüștür [16]. Bizim çalışmamızda safra asit düzeylerinin ortalamas $26.42 \pm 19.1 \mu \mathrm{mol} / \mathrm{Lidi}$. Hastaların yalnızca \%6'sinda amniyonda mekonyum izlendi; ancak, bu hastaların hiçbirinde safra asit düzeyi $40 \mu \mathrm{mol} / \mathrm{L}$ üzerinde değildi.

Kolestazın en önemli komplikasyonlarından biri de prematüritedir $[17,18]$. Literatürde kolestaz hastalarında prematürite oran $1 \% 19$ ila 60 olup, spontan veya iyatrojeniktir.Çalışmalarda RDS'nin aynı gestasyonel haftada kontrol grubu hastalarla karş1laştırıldıklarında GIKK'lihastalarda daha fazla olduğu görülmüştür[19, 20]. Ayrıca bu yüksekliğin safra asit düzeylerinden bağımsız olduğu da gözlenmiştir [20]. Bizim çalışmamızda da literatür verilerine benzer şekilde artışlar tespit edildi. Çalışmamızda 53 hastanın 20'sinde (\%37.7) preterm doğum izlendi; ancak, bu hastaların yalnızca üçünde safra asit düzeyi $40 \mu \mathrm{mol} / \mathrm{L}$ üzerindeydi. Bununla birlikte, yenidoğanların \%32.7'si YYBÜ'ye alınırken \%32.7'sinde TTN,\%33.3'ünde RDS geliştiği gözlendi. Safra asit düzeyleri ile fetal komplikasyonlar arasında ilişki saptayan yayınların yanı sıra, preterm doğum,RDS ve fetal distres ile safra asit düzeyleri arasında ilişki olmadığını belirten yayınlarda mevcuttur [21, 22].

Literatürde kolestaz hastalarında ölü doğum oranı $\% 0.4$ ila \%7olarak saptanmıştır $[23,24]$.Nedeni net olarak belirlenmemişse de, kronik uteroplasental yetmezlikten ziyade, akut hipoksi nedeni ile oluştuğuna dair bulgular izlenmiştir [25]. Ölü dogum sikl1kla 37. haftadan sonra ve yüksek safra asit düzeylerine sahip hastalarda daha sik görülmektedir [26]. Fetal ölümün safra asitlerine bağlı olarak kardiyak aritmi nedeniyle oluştuğu varsayılmaktadır. Kardiyomiyositlerin safra asitleri ile karşılaşması sonucu kontraktilitelerinde azalma ve aritmojenik aktivite gösterdikleri görülmüştür [25, 27]. Amerikan Obstetrik ve Jinekoloji Derneği GíK hastaların aktif bir şekilde yönetimini desteklemektedir [28]. Yine çalışmalarda 36.gebelik haftasının neonatal ölüm ve ölü doğum ile preterm doğumun komplikasyonlarını azaltmada en uygun zaman olduğu belirlenmiştir [29, 30]. Çalışmamızda ölü doğum saptanmadı.Bunun nedeni,hastaların en geç 37 ila 38.gebelik haftalarında gebeliklerinin sonlandırılması ve şiddetli kolestaz olgularında ise doğumun daha erkene alınması olabilir.

Çalışmamızın bazı kısıtlılıkları bulunmaktadır. Bunların başında çalışmanın retrospektif tasarımli olmasi ve hasta sayisinin az olmasi gelmektedir. Ancak hastalığın seyrek görülmesi nedeniyle çalışma retrospektif olarak tasarlanmıştır. Ayrıca kliniğimizde hastalı̆̆ın aktif yönetimi nedeniyle fetal komplikasyonların daha az olduğu görülmüsstür.

Sonuç olarak,GİK'in takibinde en önemli unsurlar olan perinatal mortalite ve morbiditeyi azaltmak için hastaların yakın takibi ve şiddetli kolestaz bulguları olan hastaların belirlenip uygun tedavinin erken başlanması oldukça önemlidir.Her hasta için ayrı takip ve tedavi planının belirlenmesi, preterm doğumların ve olumsuz perinatal sonuçların engellenmesi açısından önem arz etmektedir. 


\section{KAYNAKLAR}

1. Diken Z,Usta IM, Nassar AH. A clinical approach to intrahepatic cholestasis of pregnancy.Am J Perinatol2014;31:1-8.

2. Estiu MC,Monte MJ, Rivas L, et al. Effect of ursodeoxycholic acid treatment on the altered progesterone and bile acid homeostasis in the mother-placenta foetus trio during cholestasis of pregnancy. Br J Clin Phramacol 2015;79:316-29.

3. Brouwers L, Koster MP, Page-Christiaens GC, et al. Intrahepatic cholestasis of pregnancy: maternal and fetal outcomes associated with elevated bile acid levels. Am J Obstet Gynecol 2015; 212: 100. e1-7.

4. Williamson C, Geenes V. Intrahepatic cholestasis of pregnancy. Obstet Gynecol 2014; 124: 120-133

5. Parizek A, Hill M, Duskova M, Vitek L, Velikova M, Kancheva R. A comprehensive evaluation of steroid metabolism in women with intrahepatic cholestasis of pregnancy. PLoS One 2016;11:e0159203.

6. Cui D, Zhong Y, Zhang L, et al. Bile acid levels and risk of adverse perinatal outcomes in intrahepatic cholestasis of pregnancy: A meta-analysis. J Obstet Gynaecol Res. 2017; 43(9): $1411-1420$

7. Biberoglu E, Kirbas A, Daglar K, et al. Role of inflammation in intrahepatic cholestasis of pregnancy. J Obstet Gynaecol Res 2016; 42: 252-257.

8. Puljic A, Kim E, Page J, et al. The risk of infant and fetal death by each additional week of expectant management in intrahepatic cholestasis of pregnancy by gestational age. Am J Obstet Gynecol 2015; 212: 667.e1-5.

9. Wikström Shemer E, Marschall H, Ludvigsson J, Stephansson $O$. Intrahepatic cholestasis of pregnancy and associated adverse pregnancy and fetal outcomes: a 12-year population-based cohort study. BJOG 2013; 120: 717-723

10. Martineau M, Raker $C$, Powrie R, et al. Intrahepatic cholestasis of pregnancy is associated with an increased risk of gestational diabetes. Eur J Obstet Gynecol Reprod Biol 2014; 176: 80-85.

11. Raz Y, Lavie A, Vered Y, et al. Severe intrahepatic cholestasis of pregnancy is a risk factor for preeclampsia in singleton and twin pregnancies. Am J Obstet Gynecol 2015; 213: 395 e1-8

12. Estiú MC, Frailuna MA, Otero C, et al. Relationship between early onset severe intrahepatic cholestasis of pregnancy and higher risk of meconium-stained fluid. PLoS One. 2017; 12(4): e0176504

13. Mor M, Shmueli A, Krispin E.et al.Intrahepatic cholestasis of pregnancy as a risk factor for preeclampsia.Arch Gynecol Obstet 301,655-664 (2020).

14. Shemer WE, Marschall HU, Ludvigsson JF, Stephansson O(2013) Intrahepatic cholestasis of pregnancy and associated adverse pregnancy and fetal outcomes: a 12-year population-based cohort study. BJOG 120(6):717-723

15. Kawakita T, Parikh LI, Ramsey PS, et al. Predictors of adverse neonatal outcomes in intrahepatic cholestasis of pregnancy. Am J Obstet Gynecol. 2015; 213(4): 570.e1-570.e8

16. Glantz A, Marschall HU, Mattsson LA. Intrahepatic cholestasis of pregnancy: Relationships between bile acid levels and fetal complication rates. Hepatology. 2004; 40(2): 467-474
17. Campos GA, Castillo RJ, Toro FG. [Effect of bile acids on the myometral contractility of the isolated pregnant uterus]. Rev Chil Obstet Ginecol. 1988; 53(4): 229-233

18. Germain AM, Kato S, Carvajal JA, et al. Bile acids increase response and expression of human myometrial oxytocin receptor. Am J Obstet Gynecol. 2003; 189(2): 577-582

19. Arthuis C, Diguisto C, Lorphelin H, Dochez V ,Simon E,Perrotin F, Winer N.Perinatal outcomes of intrahepatic cholestasis during pregnancy: An 8-year case-control study.PLoS One 2020; 15(2): e0228213

20. Zecca E, De Luca D, Marras M, Caruso A, Bernardini $T$, Romagnoli $C$. Intrahepatic cholestasis of pregnancy and neonatal respiratory distress syndrome. Pediatrics. 2006; 117(5):1669-72

21. Madazli R, Yuksel MA, Oncul M, et al. Pregnancy outcomes and prognostic factors in patients with intrahepatic cholestasis of pregnancy. J Obstet Gynaecol. 2015; 35(4): 358-361

22. Oztas E, Erkenekli K, Ozler $S$, et al. Can routine laboratory parameters predict adverse pregnancy outcomes in intrahepatic cholestasis of pregnancy? J Perinat Med. 2015; 43(6): 667-674

23. Geenes V, Chappell LC, Seed PT, Steer PJ, Knight M, Williamson C. Association of severe intrahepatic cholestasis of pregnancy with adverse pregnancy outcomes: a prospective population-based case-control study. Hepatol Baltim Md. Avr 2014; 59(4):1482-91.

24. Williamson C, Hems LM, Goulis DG, Walker I, Chambers J, Donaldson $O$, et al. Clinical outcome in a series of cases of obstetric cholestasis identified via a patient support group. BJOG Int J Obstet Gynaecol. juill 2004; 111(7):676-81.

25. Williamson C, Gorelik J, Eaton BM, et al. The bile acid taurocholate impairs rat cardiomyocyte function: a proposed mechanism for intra-uterine fetal death in obstetric cholestasis. Clin Sci (Lond). 2001; 100(4): 363-369

26. Ovadia C,SeedPT,Sklavounos A, Geenes V, Di Illio C, Chambers $J$, et al.Association of adverse perinataloutcomes of intrahepatic cholestasis of pregnancy with biochemical markers: results ofaggregate and individual patient data meta-analyses.Lancet.2019;393(10174): 899-9092.

27. Miragoli M, Kadir SH, Sheppard MN, et al. A protective antiarrhythmic role of ursodeoxycholic acid in an in vitro rat model of the cholestatic fetal heart. Hepatology. 2011; 54(4): $1282-1292$

28. ACOG Committee Opinion No. 764: Medically Indicated Late-Preterm and Early-Term Deliveries. Obstet Gynecol. 2019 Feb; 133(2):e151-e155

29. Quigley MA, Poulsen G, Boyle E, Wolke D, Field D, Alfirevic $Z$, et al. Early term and late preterm birth are associated with poorer school performance at age 5 years: a cohort study. Arch Dis Child Fetal Neonatal Ed. mai 2012; 97(3):F167-173

30. Chappell LC, Gurung V, Seed PT, Chambers J, Williamson $C$, Thornton JG, et al. Ursodeoxycholic acid versus placebo, and early term delivery versus expectant management, in women with intrahepatic cholestasis of pregnancy: semifactorial randomised clinical trial. BMJ. 13 juin 2012; 344:e3799 